\title{
A educação como prática de cultura na Amazônia
}

\author{
Education as a culture practice in the Amazon \\ La educación como práctica de la cultura en la Amazonía
}

\author{
Laura Belém Pereira \\ ORCID: https://orcid.org/ 0000-0002-5830-0255 \\ Universidade Federal do Amazonas, Brasil \\ E-mail: laura_belem@outlok.com \\ Cassandra Augusta Rodrigues Nascimento \\ ORCID: https://orcid.org/0000-0003-1520-6282 \\ Universidade Federal do Amazonas, Brasil \\ E-mail: cassandraaugusta@gmail.com \\ Valéria Augusta Cerqueira de Medeiros Weigel \\ ORCID: https://orcid.org/0000-0002-1247-5674 \\ Universidade Federal do Amazonas, Brasil \\ E-mail: valeriawegeil@hotmail.com \\ Hellen Cristina Picanço Simas \\ ORCID: https://orcid.org/0000-0001-9637-6587 \\ Universidade Federal do Amazonas, Brasil \\ E-mail: india.parintintins@gmail.com \\ Reinaldo Oliveira Menezes \\ ORCID: https://orcid.org/ 0000-0002-9207-7886 \\ Universidade Federal do Amazonas, Brasil \\ E-mail: reinaldo_bamn01@hotmail.com
}

\begin{abstract}
Resumo
Este artigo tem por objetivo refletir acerca de questões sobre educação e cultura na Amazônia, sob o viés antropológico e interdisciplinar. Trata-se de um estudo de cunho bibliográfico. Neste sentido, a proposta é pensar a educação e a cultura como dimensões do processo social, considerando a emergência de novas tecnologias e suas interações com culturas locais e globais vigentes. A reflexão aqui exposta, ao mesmo tempo, direciona-se a pensar o papel da educação institucional e da educação popular no contexto das relações sociais que permeiam escolasociedade/docentes-discentes. Assim, as leituras de abordagem interdisciplinar, proporcionaram uma aproximação do cotidiano escolar amazônico e de suas interações em meio a situações que envolvem processos da educação e suas transformações no mundo globalizado.
\end{abstract}

Palavras-chave: Ensino; Educação; Cultura; Amazônia; Prática.

\begin{abstract}
This article aims to reflect on questions about education and culture in the Amazon, under an anthropological and interdisciplinary bias. This is a bibliographic study. In this sense, the proposal is to think of education and culture as dimensions of the social process, considering the emergence of new technologies and their interactions with current local and global cultures. The reflection exposed here, at the same time, has the purposes to think about the role of institutional education and popular education in the context of social relations that permeate school-society / teachersstudents. Therefore, the readings of an interdisciplinary approach, provided an approximation of the Amazonian school daily life and its interactions in the midst of situations that involve education processes and their transformations in the globalized world.
\end{abstract}

Keywords: Teaching; Education; Culture; Amazon; Practice.

\section{Resumen}

Este artículo tiene como objetivo reflexionar sobre cuestiones sobre educación y cultura en la Amazonía, bajo un sesgo antropológico e interdisciplinario. Este es un estudio bibliográfico. En este sentido, la propuesta es pensar en la educación y la cultura como dimensiones del proceso social, considerando el surgimiento de las nuevas tecnologías y sus interacciones con las culturas locales y globales actuales. La reflexión aquí expuesta, al mismo tiempo, tiene como objetivo pensar en el papel de la educación institucional y la educación popular en el contexto de las relaciones sociales que permean escuela-sociedad / docentes-alumnos. Así, las lecturas de un enfoque interdisciplinario, brindaron una aproximación a la vida cotidiana de la escuela amazónica y sus interacciones en medio de situaciones que involucran procesos educativos y sus transformaciones en el mundo globalizado.

Palabras clave: Ensenãnza; Educación; Cultura; Amazonía; Práctica. 


\section{Introdução}

A questão da educação na Amazônia passa pela dimensão do pluralismo cultural que dá forma às suas diversas identidades. Neste espaço sociocultural é possível citar a existência da educação do campo, educação indígena, educação quilombola, educação urbana, como eixos de formação escolarizada na Amazônia. A Amazônia é constituída por uma diversidade sociocultural que abarca muitas etnias, denominadas pela sociedade envolvente como povos indígenas, quilombolas, ribeirinhos e caboclos (Lousada, Costa \& Santos, 2020; Oliveira, Peixoto \& Maio, 2019; Morales, Sánchez e Zúñiga, 2017; Pereira \& Pereira, 2020).

Tais grupos étnicos tem formas próprias de se auto reconhecerem enquanto sujeitos sociais amazônicos. Os denominados povos indígenas são: Tikuna, Tukano, Sateré-Mawé, Wai-wai, Munduruku, Dessana, Baniwa, Pirarrãs, entre outros. Possuem formas próprias de educar suas crianças em seus espaços socioculturais ancestralmente demarcados ou de recente ocupação.

Os denominados ribeirinhos, muitas vezes se identificam pela localidade em que vivem, pelas características geográficas e socioculturais de seus territórios, Terra firme, Terra de Várzea, entre outras variações de local. Possuem formas específicas de educar suas crianças para a interação com o meio social inserido.

Os chamados caboclos, por sua vez, também encontram diversidade polissêmica para expressar sua identidade em um constante processo de transformação. Residem em cidades de pequeno e médio porte, comunidades rurais e urbanas, residem em metrópoles, realizam atividades laborais e desempenham diversas funções em seus grupos sociais (Mezzaroba, 2020; Nascimento, Souza \& Simas, 2021).

Há diferenças e singularidades entre os vários sujeitos amazônicos, mas há também semelhanças entre ambos, pois passam por constantes transformações e reelaborações de suas identidades no contexto de interação social, econômica, cultural e política do mundo globalizado (Nascimento, Souza \& Simas, 2021).

É a partir da diversidade de identidades socioculturais de sujeitos amazônicos e suas ambiências, das experiências vivenciadas dentro e fora de suas localidades e, por meio de suas atuações diretas ou indiretas, que é formado o contexto cultural da questão da Educação Amazônica. Os sujeitos sociais amazônicos são docentes, discentes, técnicos e/ou especialistas educacionais, pais, comunidade, agentes estatais ou empresariais, todos partindo de um lugar de vivência e, agindo de acordo com interesses políticos, econômicos e sociais (Pereira \& Pereira, 2020; Peixoto \& Santos, 2021).

Neste sentido, o decorrer deste artigo propõe a partir dos autores elencados pensar e repensar a Educação na Amazônia a partir de sua historicidade, destacando recortes importantes de diferentes realidades em que os sujeitos sociais da educação, sob condições predeterminadas, política e economicamente construíram nessa região.

\section{Metodologia}

O presente trabalho tem como abordagem a pesquisa qualitativa e a pesquisa bibliográfica. De acordo com os autores, Koche (2011), Ludke e André (2013), Pereira et al. (2018), a pesquisa qualitativa percorre na atualidade todo um campo transdisciplinar, pois envolve as ciências humanas e sociais e um arcabouço teórico de múltiplos paradigmas, a exemplo, fenomenologia, construtivismo, marxismo.

Neste prisma, Pereira et al. (2018, p. 67) salientam que a pesquisas qualitativas "são aqueles nos quais é importante a interpretação por parte do pesquisador com suas opiniões sobre o fenômeno em estudo. Neles a coleta de dados muitas vezes ocorre por meio de entrevistas com questões abertas. Neste tipo de pesquisa algumas características”. Isto é, a pesquisa qualitativa viabiliza a interpretação de fatos e experiências individuais e coletivos por meio de análise como a antropológica que é por ênfase interdisciplinar. Desde modo, pesquisadores podem extrair do meio social traduções e intepretações sobre o 
cotidiano em estudo, utilizando a perspicácia e competência científica para a produção de conhecimento sobre uma dada dimensão do processo social investigado (Koche, 2011; Ludke \& André, 2013; Pereira et al., 2018).

E no que tange a pesquisa bibliográfica é aquela,

[...] que se desenvolve tentando explicar um problema, utilizando o conhecimento disponível a partir das teorias publicadas em livros ou obras congêneres. Na pesquisa bibliográfica o investigador irá levantar o conhecimento disponível na área, identificando as teorias produzidas, analisando-as e avaliando sua contribuição para auxiliar a compreender ou explicar o problema objeto da investigação (Koche, 2011, p. 122).

Deste modo, o presente estudo recorreu a autores cujas narrativas e análises teóricas aqui elencadas, trazem discussões sobre a questão da Educação na Amazônia, assim como discussões mais globais; apresentadas nas leituras de autores de vertente interdisciplinar, favorecendo o diálogo entre os campos de saberes da Antropologia e Educação para além de fronteiras meramente monodidáticas.

Sendo assim, a partir do material elaborado por Carneiro e Weigel (1989) no final da década de 1980, limiar dos anos 90, propõem-se repensar a construção da educação como prática de cultura na Amazônia a partir de sua historicidade. Na perspectiva de construção interdisciplinar os autores Edgar Morin (2003); McLaren (2013); Stuart Hall (2014) dialogam com a visão de educação para diversidade e pluralidade de saberes.

\section{Resultados e Discussão}

\subsection{Educação e cultura}

O imaginário amazônico é fonte de uma riqueza imensurável de contos, lendas, narrativas indígenas, caboclas, ribeirinhas e quilombolas. O processo de assimilação desse acervo oral inicia-se na maioria das vezes no ambiente familiar, para algumas crianças o contato com as histórias da região começa antes mesmo de adentrar no ambiente escolar (Serpa et al., 2021).

Deste modo, a cultura amazônica por meio de suas narrativas desperta a curiosidade infantil e pode contribuir para a formação do gosto pela leitura, a leitura de mundo, a leitura da codificação e a decodificação provenientes do processo de alfabetização (Serpa et al., 2021).

Por meio das práticas culturais a criança constrói suas primeiras narrativas, sua compreensão do mundo ao entorno, adquire conhecimentos e valores humanos. Ao adentrar na escola a criança amplia sua visão de mundo e necessita que o ambiente escolar contribua para o fortalecimento de sua identidade sociocultural em formação (Lima, Nunes \& Braga, 2020; Nascimento, Souza \& Simas, 2021; Marque \& Carvalho, 2019).

Barreto (1998) e Peixoto e Santos (2021) alertam para a necessidade de relembrar continuamente que a educação é o meio pelo qual a pessoa se torna mais humana. À medida que se deixa de lado a vocação de ser mais, homens e mulheres se desumanizam e predomina a relação desigual dos privilégios para si em detrimento da perda do outro.

A cultura representa a própria cartografia das relações sociais das pessoas ao longo da vida. Por meio da cultura amazônica, homens e mulheres se identificam com seus grupos sociais e se definem, sob certas condições, indígenas, ribeirinhos, quilombolas, pescadores, agricultores, entre outros.

A diversidade cultural expressa a pluralidade de saberes praticados em uma mesma comunidade, cidade, grupo religioso, folclórico, étnico, escolar, podendo ressaltar diversas habilidades, entre elas as habilidades artísticas como o desenho, pintura, danças, trançados, etc.

Edgar Morin (2003) destaca o termo "cultura das humanidades", a fim de propor uma reflexão sobre a palavra cultura em seu sentido antropológico de conexão com as formas de conhecimento, valores e símbolos que orientam e guiam vidas 
humanas. Embora, o termo cultura ainda seja relacionado como sinônimo de elite, se faz importante entender a cultura como processo de preparação para a vida.

A condição humana é permeada por lutas e embates dos sujeitos sociais na busca de exaltar sua distinção entre a natureza de outros animais e as ações da humanidade. Esse tem sido um exercício constante na intrínseca relação entre cultura e educação: destacar a capacidade humana de transformar a natureza, de criar símbolos, significar e (re) significar seus processos de interação com o meio. Toda essa trama tem configurado a educação como elemento da cultura, e de sua relação com sistemas culturais internos e externos ao meio inserido (Rocha \& Tosta, 2013).

Neste sentido, a ciência antropológica tem oferecido subsídios para a educação desenvolver-se a partir das possibilidades de aprofundamento no campo dos debates sobre a cultura como dimensão fundadora da sociedade humana. A cultura tem sido um permanente objeto de estudo sobre a humanidade (Rocha \& Tosta, 2013).

Morin (2003, p. 41) expõe como paradoxo recorrente, no campo das ciências humanas, "o desafio de repensar sua contribuição ao estudo da condição humana, sobretudo, em um momento em que a fragmentação das áreas de conhecimento limita o desenvolvimento de uma complementariedade entre os campos de saberes".

Apesar do norteamento que a interdisciplinaridade aponta para o desenvolvimento das ciências humanas, estas se encontram, ainda, desligadas da necessária conexão na busca da compreensão da intrínseca relação “individuo/espécie/sociedade. Para tanto, "seria necessário conceber uma ciência antropossocial religada", cuja concepção de humanidade considere a unidade antropológica e suas diversidades individuais e culturais (Morin, 2003; Silva, 2019).

Contudo, pensar uma ação pedagógica interdisciplinar em um sistema educacional que se encontra segmentado e dividido em disciplinas hierarquizadas, exige uma força tarefa dos responsáveis pela realização das práticas educacionais vigentes, pois "é preciso desenvolver competências e não apenas formar reprodutores de modelos já estabelecidos. Formar cidadãos com valores, virtudes, com capacidade de gerenciar suas emoções e pensamentos” (Testa, 2020, p. 9).

Em meio a esta reflexão, uma das possibilidades pertinentes seria pensar em uma prática educadora na Amazônia a partir de uma "genealogia reflexiva, viés do multiculturalismo, cuja percepção envolve o raciocínio de uma educação que possa transformar o senso comum em conhecimento natural". Assim, seria viável valorizar a base cultural e dimensionar novas formas de ler o mundo amazônico e suas distintas representações na sociedade (Mclaren, 2000, p. 49).

A reflexão proposta por Peter McLaren (2000, p. 51) diz respeito a uma Pedagogia crítica, cuja abordagem requer "repensar o sujeito social sob o viés das mudanças na esquerda tradicional estadunidense". Contudo, tal reflexão pode ser repensada em diferentes contextos, como é o caso amazônico, cujo espaço social e geográfico encontrasse constantemente em discussão no cenário mundial político e ambiental.

O autor analisa a partir de características dos novos tempos (proliferação de cenários de antagonismos e resistências, manifestação de novas subjetividades, novos movimentos sociais, novas identidades coletivas) a necessidade de repensar a educação e suas frentes de luta. Mediante a esfera ampliada do cenário político e seus novos coletivos que apoiam a mudança, a perspectiva era de construção progressista, ainda que essa transformação não seja nada simples de se realizar (Mclaren, 2000; Peixoto \& Santos, 2021).

Ao pensar as novas identidades coletivas e o cenário político, insere-se aqui o caso das transformações socioeconômicas e culturais vivenciadas pelos povos amazônidas na cidade de Manaus e seu entorno na segunda metade do século XX. Tal cidade passou por profundas mudanças no contexto de adaptação e construção de novas identidades em seu território, motivadas, sobretudo pela implantação de projetos econômicos para a região.

No período de 1960 a 1990 a região amazônica passou pela efervescência da expansão da fronteira econômica em seus estados e obviamente esse processo resultou em profundas mudanças no contexto de vida das culturas locais, resultando em processos de migrações internas e externas ao estado do Amazonas. 
As políticas de desenvolvimento para a região envolviam o processo de ocupação do território e a constante preocupação do estado nacional na integração da Amazônia ao restante do país. O cenário da década de 1950, foi marcado pelo fracasso da economia da "Batalha da Borracha" e, posteriormente deu-se início a implantação dos grandes projetos de desenvolvimento para a região (Santos, Machado \& Seráfico, 2015).

Neste contexto, após o fim do ciclo da borracha, o cenário econômico do município de Manaus caracterizava-se por uma modesta renda gerada pelo extrativismo vegetal, pequenas indústrias de alimentos e por transferências realizadas pelo governo federal. Os empregos em geral estavam alocados no frágil comércio, serviço público e pequenas indústrias de beneficiamento de produtos regionais, alimentícios e artigos de uso doméstico. A baixa densidade demográfica contribuía na inviabilidade econômica de atividades ali alojadas (Bentes, 1983 apud Santos, Machado \& Seráfico, 2015; Fuentes Felicó, 2017).

Em meio a esse processo de inserção econômica no cenário nacional, a região vivenciou as contradições da condição humana em meio as lutas e embates dos sujeitos sociais na busca de enaltecer sua distinção entre a natureza de outros animais por meio das ações da humanidade. O exercício da cultura e da educação, desdobradas sob a capacidade humana de transformar a natureza, criar símbolos, significar e (re)significar seus processos de interação com o meio, tem configurado toda educação como elemento da cultura, e de sua relação com sistemas culturais internos e externos ao meio inserido (Rocha \&; Tosta, 2013).

A proposta antropológica direciona-se sob o olhar mais alargado e descentralizado, pela capacidade de captar dimensões da condição humana e suas complexas tramas sociais, construídas por sujeitos sociais sob condições historicamente determinadas. No campo da educação, a Antropologia se constitui como uma ciência interdisciplinar, cuja intencionalidade está em buscar conhecer o homem sob todas suas dimensões - conforme Mauss, 'o homem total' (Rocha \& Tosta, 2013).

Um olhar mais alargado sobre a questão da educação na Amazônia, por sua vez, requer a capacidade de perceber as múltiplas dimensões da condição humana como ela se apresenta para diferentes povos, a partir das experiências vividas por indígenas do Alto Solimões, do Baixo Amazonas, por quilombolas inseridos em territórios rurais ou urbanos, ribeirinhos da região de várzea ou terra firme, região de fronteira interestaduais ou internacionais. Assim, perceber o sujeito total amazônico exige olhares diferenciados e extremamente atentos as dinâmicas locais e globais.

$\mathrm{Na}$ esfera global o desafio está na compreensão do processo de mundialização da economia, no modo como se estabelecem as mudanças, na forma como sujeitos sociais passam a reivindicar a autonomia frente as formas de massificação das culturas locais. A resistência contra a suposta homogeneização cultural tem sido representada nas tentativas de afirmação de singularidades étnicas, religiosas, de gênero, língua, entre outros. Assim, não se deve desconsiderar as contradições políticas e econômicas do campo cultural e sua influência na educação (Rocha \& Tosta, 2013).

O autor Josué de Castro (1980 apud Carneiro \& Weigel, 1989), no prefácio do livro 'Geografia da fome’, em sua décima edição, evidencia a Amazônia como uma área marcada pela fome, pela carência nutricional de mais de cinquenta por cento de suas crianças. Essa constatação, sustenta o pensamento de que não se pode ignorar a questão do desenvolvimento e distribuição econômica na Amazônia. É um erro de inteira responsabilidade de quem faz educação na região, negar tal questão.

Em meados da década de 1960 é criada em Manaus a Zona Franca, constituída como uma das principais ações governamentais para ocupar e desenvolver a Amazônia. Para dar subsídio ao empreendimento é criado a SPEVEA e posteriormente sua substituta a SUDAM, órgãos de controle do governo federal na região. O Decreto-lei que criou a ZFM criou também a autarquia responsável pela sua administração, a Superintendência da Zona Franca de Manaus (SUFRAMA), cujas atribuições estavam elaborar e executar programas e projetos de interesse da ZFM e de articulação com as demais instituições federais, estaduais ou municipais para o desenvolvimento da ZFM (Santos, Machado \& Seráfico, 2015).

Na época da criação da Zona Franca, década de 1960, a população do estado era predominantemente rural. A 
esperança de obter um emprego na ZFM influenciou no crescimento da migração de pessoas do interior e de outros estados para a capital Manaus. Em menos de duas décadas a população urbana havia superado o contingente populacional rural. Porém, o crescimento urbano na cidade de Manaus resultou no aumento de uma população de baixa renda. Pode-se concluir que a ZFM serviu para a organização de um mercado de trabalho capitalista na região. A instalação das indústrias levou a formação de um mercado de trabalho mais regular (fixação de salários, garantias, direitos e benefícios trabalhistas). Assim, a ZFM foi a alternativa tardia à economia da borracha e de modo específico atuou na integração da região à divisão internacional do trabalho e à dinâmica do capitalismo global (Santos, Machado \& Seráfico, 2015).

Ressalta-se que as mudanças na esfera econômica interferem direta ou indiretamente nos processos educacionais de diferentes povos. De modo, a contribuir para o seu fortalecimento ou não das identidades locais, haja vista, o modelo de educação tecnicista direcionado para formação de mão de obra direcionada ao mercado de trabalho.

A proposta da Pedagogia Crítica, neste sentido é capacitar seus praticantes a falar com autoridade, sem, contudo, ser autoritário. É uma pedagogia que possibilita pensar nas identidades amazônicas a partir da desconstrução da visão naturalizada de subordinação ao modelo de educação positivista. A pedagogia crítica tem a intencionalidade de atuar na construção de uma visão intelectual inovadora, no sentido de fortalecer as lutas anticapitalistas, anti-racistas, anti-sexistas, anti-homófobicas e anticolonialistas. A pedagogia crítica trás o discurso da esperança de novas possibilidades frente a visão limitada de sucesso ou fracasso da pessoa inserida ou marginalizada no sistema capitalista (Mclaren, 2000).

Hall (2006) acrescenta que o papel descentralizador do efeito da globalização tem disseminado na sociedade moderna uma ruptura da visão moderna de sociedade, caracterizada pela ideia definida de solidez da identidade nacional. A globalização, nesse ponto de vista potencializa a emergência ou formação de novas identidades locais.

Na percepção de Morin (2003, p. 47) “é preciso ensinar a viver para além dos conhecimentos escolarizados”. Para Morin, todo individuo é um ser bio-psico-socio-espiritual. Neste sentido é papel dos responsáveis pela educação, profissionais e sociedade, exercer práticas educadoras que desenvolvam adequadamente o ser mental de cada indivíduo, possibilitando o pleno desenvolvimento da capacidade de transformação de conhecimento adquirido em sapiência. À educação, cabe a função de orientar para a transformação de informações em conhecimento e deste em sapiência (Marque \& Carvalho, 2019).

Em relação a Amazônia, é imprescindível buscar uma nova concepção de desenvolvimento, como propõem Boaventura de Souza Santos, um desenvolvimento alternativo, de ruptura ao modelo hegemônico. A nova forma de produção da sociedade moderna tem exigido processos produtivos globalizados, flexibilização nos direitos trabalhistas, padrões cada vez mais caros à qualidade de vida e aquisição de direitos à justiça social no mundo do trabalho (Loureiro, 2012).

Essa forma de conceber o desenvolvimento econômico exclui a maioria dos modos de vida econômico dos povos da Amazônia em seus espaços de produção da vida. Contudo, o final do século XX, revelou que o futuro da humanidade não é teleguiado pelo progresso histórico e não pode ser mensurado por prenúncios de um futuro econômico friamente calculado. As crises do presente têm exposto a sociedade global as incertezas da vida (Morin, 2003).

Neste sentido, Morin (2003) alerta sobre a essência da contribuição da cultura científica para a humanidade, "pensar a condição humana" no tempo presente, de acordo com as condições sociais, naturais, econômicas e culturais que se apresentam os sujeitos sociais, afinal a condição humana é marcada pelas incertezas da vida tanto no campo cognitivo quanto histórico.

A proposta de ruptura, a descontinuidade, desloca, desarticula as identidades estáveis do passado, contudo, também abre novas possibilidades de articulações, a fim de criar novas identidades, elaborar novas produções de sujeitos e, contribuir para a 'recomposição da estrutura em torno de pontos nodais particulares de articulação' (Laclau, 1990, apud Hall, 2006).

A sociedade não como os sociólogos pensaram muitas vezes, um todo unificado e bem delimitado, uma totalidade, produzindo-se através de mudanças evolucionárias a partir de si mesma, como o desenvolvimento de uma flor a partir de seu bulbo. Ela está constantemente sendo "'descentrada" ou deslocada por forças fora de si mesma (Hall, 2006). 
A fim de manter uma estrutura de unidade entre os indivíduos, o Estado nacional empregou tais recursos, visando não perder sua composição. Tais elementos bem articulados serviram para que o Estado nacional, mantivesse sua hegemonia durantes anos, sob o discurso de uma identidade nacional unificada e conexa.

É preciso pensar sob quais condições e possibilidades os estudantes subalternos estão inseridos e quais meios dispõem para atuar na transformação de preceitos ideológicos historicamente naturalizados nas relações sociais de poder e privilégios. Esta reflexão envolve e diz respeito a qual capacidade contra hegemônica as pessoas subalternas têm para gerar novas epistemologias, novas epistemes de resistência prática e teórica. A pedagogia crítica exerce papel fundamental para o fortalecimento da motivação dos sujeitos subalternos na criação de projetos de possibilidade de concretização do discurso de esperança (Mclaren, 2000).

"O exercício da pedagogia crítica, dirige-se, sobretudo, aos educadores a serviço de uma pedagogia cuja razão de ser é destinar-se às pessoas pobres, despossuídas e oprimidas. A educação deve estar a serviço da interrogação”. A educação tem a função de romper com mitos e sistemas de ensino que legitimam a desigualdade de classes ao longo de gerações. A pedagogia crítica questiona sistemas de inteligibilidade disciplinar e centralizados (Mclaren, 2000, p. 52).

Uma educação para a liberdade, exige a ultrapassagem de muitos desafios, lançados as educadoras nesse novo século. Entre os desafios está o desenvolvimento justo e sustentável das fronteiras que separam as partes subdesenvolvidas do mundo, no próprio país e no exterior (Gilroy, 1993, apud Mclaren, 2000).

O novo século apresenta o desafio de trabalhar sob um novo tipo de solidariedade, reunidos, apesar das diferenças, em prol ao desenvolvimento de uma base comum de luta, onde predomine a justiça social, cultural e econômica, e vigore um renascimento e transformação da democracia (Mclaren, 2000).

A interdisciplinaridade por meio de práticas pedagógicas, currículos, processos de formação do professor e do aluno possibilita a inserção de diálogos mais autênticos no campo da construção de projetos políticos pedagógicos complementares entre ciência e cotidiano social. A partir do exposto, nota-se que não é mais possível pensar uma educação a partir de uma única disciplina, situada fora da realidade social. A tessitura social que se apresenta é de que os processos educacionais são múltiplos e necessitam de uma dinâmica social fora e dentro da escola (Rocha \& Tosta, 2013).

A escola necessita ser um ambiente de indagação, favorecendo meios para que o sujeito faça suas descobertas, relacione conteúdos sistematicamente elaborados ao cotidiano vivido. É preciso que a escola desenvolva práticas educadoras para que os sujeitos tenham condições de elaborar seus discursos e saber apresentar seus posicionamentos de forma segura e inteligível, nos diferentes espaços sociais, seja igrejas, famílias, ambientes de trabalho e etc. (Rocha \& Tosta, 2013).

Pensar a sociedade deslocada, envolve o exercício de analisar a construção e a desconstrução do conceito de ‘comunidades imaginadas', a partir da ideia de identidade nacional. Hall (2006) considera que o sentimento de comunidade só existe sustentado no emprego de cinco elementos primordiais para a manutenção e coesão da estrutura do Estado moderno. Sendo assim, elenca: a) as narrativas da nação; b) a ideia das origens; c) a invenção das tradições; d) o mito fundacional; e) a ideia de povo puro, original (Hall, 2014). "A compreensão dessas intrínsecas relações sociais, que ora se entrecruzam, corroboram e divergem é fundamental no reconhecimento de que a escola abarca um todo social complexo e sujeito a transformações em uma velocidade variável” (Rocha \& Tosta, 2013, p. 119).

No campo da teoria social, a questão da identidade vem sendo amplamente discutida, sobre o argumento de que as velhas identidades, que por tanto tempo estabilizaram o mundo social, estão em decadência. Aborda-se o surgimento de novas identidades. O indivíduo moderno, visto anteriormente como um sujeito unificado, passa a ser analisado como um ser fragmentado. Inaugura-se a discussão da chamada "crise de identidade", cuja essência está em um processo amplo de mudança que o desloca das estruturas, dos processos centrais nas sociedades modernas. Tal situação abala os quadros de referência que davam aos indivíduos uma ideia de estabilidade no mundo social. (Hall, 2006, p. 07). 
Para entender essa mudança de paradigma, Hall (2006) apresenta pelo menos três concepções diferentes de identidades, a saber: 1) a do sujeito do Iluminismo; 2) a do sujeito sociológico e, 3) a do sujeito pós-moderno.

A primeira baseia-se numa concepção de pessoa humana como indivíduo totalmente centrado, unificado (razão consciência - ação: identidade do sujeito centrada no eu, concepção individualista). A segunda concepção diz respeito a noção de sujeito formado a partir da relação com outras pessoas, importantes para si na mediação de valores, sentidos e símbolos da cultura do mundo que habita, concepção interativa da identidade e do eu. A terceira concepção, é o sujeito pós-moderno, cuja identidade não fixada, é formada e transformada continuamente, definida historicamente. O sujeito pós-moderno assume identidades diferentes em diferentes momentos (Hall, 2006).

A identidade, enquanto termo antologicamente suscetível de análise, refere-se a mudança na modernidade tardia, cuja globalização e seu impacto sobre a identidade cultural acarretou mudanças na percepção com que os sujeitos sociais percebiam a si mesmos e seus pares. Hall (2006), citou Marx para afirmar seu pensamento sobre a modernidade:

[...] é o permanente revolucionar da produção, o abalar ininterrupto de todas as condições sociais, a incerteza e o movimento eterno ... Todas as relações fixas e congeladas, com seu cortejo de vetustas representações e concepções, são dissolvidas, todas as relações recém-formadas envelhecem; antes de poderem ossificar-se. Tudo que é sólido se desmancha no ar (Marx \& Engels, 1973, p.70 apud Hall, 2006).

Assim, a ideia prevalecente acerca das sociedades modernas, é a de sociedade de mudanças constantes e rápidas. Anthony Giddens argumentava que 'nas sociedades tradicionais, o passado é reverenciado e os símbolos são valorizados, pois contêm e perpetuam a experiência de gerações’. A tradição é vista como um meio de lidar com o tempo e o espaço, ao propor a inserção de qualquer atividade ou experiência particular para dar continuidade ao passado, presente e futuro, estruturalmente engendrados por práticas sociais recorrentes (Giddens, 1990 apud Hall, 2006, p. 37-38).

Porém, já na pós-modernidade essa estrutura se encontraria em desmoronamento, ao ponto que a visão de que o Estado Nacional seria capaz de manter seus membros unidos em torno de uma mesma identidade cultural já não se sustenta mais como antes. A ideia de uma "grande família nacional", vem sendo discutida. Entre os apontamentos discutidos estão a formação das nações modernas e seu aspecto de sobreposição violenta as culturas diferentes. A diversidade étnica. A sobreposição das nações ocidentais e sua marca de dominação imperialista e neocolonialista.

Sendo assim, as diferentes contribuições dos autores supracitados, evidenciam o surgimento de novas facetas dos sujeitos sociais na sociedade moderna, considerando que a educação é uma instituição que lida com a diversidade de identidades, é primordial que educadoras/es de diferentes instituições e níveis de ensino estejam dispostas a pensar e (re) pensar as conjunturas sociais que vivem os diversos discentes em tempos de crises, de paradigmas políticos, ideológicos, sexistas.

\subsection{A questão da Educação na Amazônia}

Historicamente a questão da educação está intimamente relacionada com o tipo de trabalho que uma determinada sociedade realiza, pois a educação é instrumento de produção e reprodução de conhecimento, podendo estar a serviço da mudança ou mesmo da manutenção de um sistema. Por isso, a questão da educação é peça central em toda e qualquer discussão sobre processos socioculturais e econômicos nas mais distintas sociedades (Pereira \& Pereira, 2020).

Ao pensar a questão da Educação na Amazônia, é sempre válido destacar que sua diversidade sociocultural está distribuída por limites nacionais e internacionais que correspondem por exemplo a tríplice fronteira: Tabatinga/Brasil Letícia/Colombia - Santa Rosa Yavari/Peru, cujas territorialidades constituem uma representação da Amazônia multiétnica.

Tal relação fronteiriça de povos amazônidas, evidencia que a dinâmica das relações socioculturais, econômicas e 
históricas nessas territorialidades requer uma atenção a educação plurilíngue no âmbito escolar, compreendendo a especificidade do cotidiano de tais povos nas cidades de fronteira (Vasconcelos, 2017).

Os povos que habitam a Amazônia são denominados como indígenas, ribeirinhos, quilombolas, extrativistas e, também identificados como povos das águas, das terras e das florestas, como destaca Vasconcelos (2017). Tais povos vem travando lutas históricas para assegurar a manutenção do direito de viver em seus territórios.

O estado nacional, grileiros, posseiros, empresários do agronegócio, entre outros, tem interferido historicamente no direito dos povos amazônidas de produzir e reproduzir seus modos de vida em seus espaços. Contudo, não sem enfrentamento, pois há resistência em todas as formas de opressão impostas aos povos tradicionais. Indígenas, quilombolas, ribeirinhos, povos da floresta, vem organizando suas lutas por meio de movimentos sociais ao longo do século XX e XXI.

De acordo com Istvan Mészáros (2008) o objetivo primordial dos sujeitos que lutam contra as formas de opressão da sociedade mercantil é atingir a emancipação humana. É nesse sentido que a educação poderia ser um instrumento de mudança.

No entanto, a educação na sociedade capitalista vem servindo como ferramenta de manutenção e legitimação dos interesses dominantes, fornecendo meios para reproduzir conhecimentos necessários a expansão do sistema capitalista. A educação utilitária, vista como peça no processo de engrenagem da acumulação de capital tem estabelecido a perpetuação da ideia de naturalização das injustiças no sistema de classes (Mészáros, 2008).

É na contramão desse contexto socioeconômico, da educação vista como mercadoria, como manipulação de pessoal necessário para o trabalho da expansão do sistema capitalista, que se inserem muitos povos ribeirinhos, indígenas e quilombolas ao estabelecer em suas lutas a exigência de uma educação diferenciada, ora denominada como educação no campo, educação indígena, pedagogia da alternância, educação para a diversidade. Dessa forma, o diferencial no carácter dos processos de formação deve estar elencado com os sujeitos e com sua realidade, agregando a ação educativa que promove a discussão sobre as questões da realidade em que estão inseridos (Lima \& Silva, 2020).

A questão da educação na Amazônia, vista pela perspectiva da diversidade cultural, tem sido discutida com maior ênfase, seja nos espaços acadêmicos ou da educação popular, a partir da segunda metade do século XX. Em um momento de efervescência dos movimentos sociais na luta pela reivindicação de direitos sociais, políticos e culturais em meio ao cenário de maior abertura política no país. É o período pós-ditadura militar no Brasil, período de redemocratização do país, da renovação de esperanças, tendo como marco a elaboração da Constituição Nacional de 1988.

O relatório “A questão da educação na Amazônia”, elaborado em 1988, pela então Universidade do Amazonas, redigido por Carneiro e Weigel (1989), apresenta importantes reflexões sobre o contexto de alienação sociocultural que cercava a formação educacional na região nesse período.

As análises de tais autoras, expõem as precárias condições de armazenamento de acervos sobre o tema da educação na Amazônia, ausência e até mesmo escassez de informações sobre investigações no período de coleta de dados. Tal situação destaca a necessidade de maior atenção para a emergência da ciência e tecnologia no espaço politicamente denominado como “região Amazônica” (Carneiro \& Weigel, 1989).

Contudo, a ausência de informações também fornece base para análises críticas e as autoras supracitadas, deixam clara a compreensão de que a ausência de material e de informações são um retrato da tentativa de apagamento da historicidade dos povos que ancestralmente habitam a região. Fazia parte do projeto de desenvolvimento econômico do país, negar as subjetividades socioculturais amazônicas, a fim de inserir na região projetos políticos e econômicos de interesse da expansão capitalista, ignorando toda forma de economia local.

A região, sob o ponto de vista do desenvolvimento econômico, já foi apresentada pelas denominações, "inferno verde", "deserto verde", em suas versões mais pessimistas e, para os mais otimistas acerca do potencial da região denominaram-na de "eldorado", “ópio verde", "pulmão do mundo" ou ainda "celeiro do mundo". A denominação, seja positiva 
ou negativa, sempre esteve permeada pelo interesse de integrá-la as regiões economicamente mais desenvolvidas no país (Wagley, 1957 apud Carneiro; Weigel, 1989).

Apesar das tentativas de integralização política e econômica interferirem diretamente nos modos de vida de povos tradicionais da região amazônica, alterando até mesmo ciclos de vida nos ecossistemas geradores de fontes econômicas locais, tais projetos econômicos implantados à revelia das populações da região não se adaptaram plenamente na região, que é marcada pela diversidade presente no contexto amazônico e na convivência entre diferentes saberes, resultado de diferentes visões de mundo e modos de viver a cotidianidade (Lima \& Silva, 2020).

No campo da educação, a década de 1980 foi marcada em todo país por uma efervescência na discussão da questão da educação colonizadora, destacando o papel do livro didático como difusor de dominação ideológica e, sobretudo, descentralizado das realidades regionais e locais dos diversos espaços socioculturais brasileiros. Discutiu-se a formulação dos planos, a necessidade de uma ação política e pedagógica crítica em oposição a ideia de dominação ideológica difundida pelos livros didáticos então produzidos, cujos conteúdos privilegiavam a cultura centro-sul, considerada a mais desenvolvida do país (Carneiro \& Weigel, 1989; Habowski, Conte \& Trevisan, 2019).

Essa perspectiva da educação colonizadora, não valorizava o conhecimento dos povos ribeirinhos que aprenderam na 'escola das águas e da terra-firme o valor do olho d'água, a importância das sementes, o respeito pela mãe d'água e pela mãe do mato' (Vasconcelos, 2017).

A riqueza cultural da aprendizagem ribeirinha, abarca o reconhecimento das horas de pesca, caça, coleta de frutas, sementes, cipós, entre outros. A identificação da mudança de tempo, estações climáticas, ocorrência de fenômenos naturais como as terras caídas.

A valorização do uso de produtos que a natureza oferece em cada estação, é uma evidência do conhecimento ribeirinho e sua integração com o ecossistema local. A localização geográfica e náutica na navegação, são elementos da rede de conhecimentos ribeirinhos. Toda essa diversidade está presente na Amazônia nos aspectos do território e da territorialidade, na vegetação e na hidrografia, na cultura e na identidade dos povos amazônidas (Vasconcelos, 2017).

Loureiro (2012) expõe o peso das experiências negativas do passado recente na Amazônia, cuja implantação de modelos econômicos e suas formas de produção, não valorizavam os modos de vida das populações tradicionais da região e deixaram um legado de invisibilidade do contexto multicultural dos diferentes grupos sociais amazônicos. Na concepção da autora somente um outro modelo alternativo ao hegemônico, embora paralelo e contemporâneo a ele, pode evitar que as populações tradicionais e seus saberes desapareçam. Um caminho viável seria a ruptura com o modelo de racionalidade científica e tecnológica vigente, cuja forma de produção está centrada na exclusão e dominação equivocada do modelo eurocêntrico e estadunidense.

Seguindo esse modelo da racionalidade científica positivista, os livros didáticos produzidos em meados da década de 1980 para a região Amazônica defendiam a questão ideológica de valorização da cultura externa, sulista e capitalista. A representação da Amazônia era empobrecida e simplória, reduzida ao exótico e pitoresco folclore. A negação da diversidade cultural e as múltiplas identidades existentes na região faziam parte do projeto de integração nacional. A produção de material didático, expressava e acentuava a visão de dependência da região aos centros mais desenvolvidos do país, ampliando a desvalorização da identidade cultural amazônica.

Baran e Sweezy (apud Mészáros, 2011) enfatizaram que o igualitarismo da ideologia capitalista é uma de suas forças, que deve ser analisada e não descartada levianamente, pois, desde a infância as pessoas aprendem por todos os meios concebíveis que todos têm oportunidades iguais e o infortúnio é ocasionado pela capacidade individual.

A discussão acerca da descentralização da produção do livro didático na Amazônia, configurou um cenário de abertura à participação política. Intelectuais locais pensaram na urgência em investir na produção de material didático, a fim de 
"recuperar a identidade cultural da região amazônica, contudo, pensavam em qual concepção de identidade cultural iriam destacar (Carneiro \& Weigel, 1989).

A escolha da matriz ideológica impressa nos livros didáticos não é aleatória, ela serve aos interesses de manutenção ou transformação do status que se pretende perpetuar. Por meio da educação, a classe hegemônica tem mantido seus privilégios sob a alegoria mitológica de igualdade, proclamada na forma de igualdade de oportunidades, perpetuando seu oposto diametral na ordem vigente sob o domínio do capital (Mészáros, 2011).

Embora, a discussão da elaboração de material didático tenha alcançado de certo modo um avanço na valorização das culturas amazônicas, a produção da Cartilha da Amazônia, por sua vez, não obteve o êxito esperado. Produzida sob a linha de pensamento behavorista, tal cartilha elaborada pelo INPA e utilizada em instituições vinculadas ao INPA e na rede pública da periferia de Manaus, não atingiram resultados satisfatórios no uso do método de alfabetização estímulo-reforço.

A regionalização da produção de conteúdo de ensino local, foi realizada com base em uma teoria positivista que reforçou a ideia de "natureza" e "funcional", acentuando a divisão entre o meio rural e urbano. A zona rural, por sua vez, manteve-se enlaçada à condição de espaço de ensino aligeirado. A educação escolar na região ficou marcada pelas diferenciações entre escolas de ensino fundamental rurais e urbanas, naturalizou-se a discriminação na exigência diferenciada, na duração do período escolar e na amplitude do currículo (Carneiro \& Weigel, 1989).

É impossível imaginar-se uma educação que contribua para que as pessoas se acomodem e, ao mesmo tempo, busquem transformações. A educação ou será conservadora ou transformadora. Assim sendo, “o papel do educador não é propriamente falar ao educando, sobre sua visão de mundo ou lhe impor esta visão, mas dialogar com ele sobre a sua visão e a dele. Sua tarefa não é falar, dissertar, mas problematizar a realidade concreta do educando, problematizando-se ao mesmo tempo". Os educadores democráticos não estão - são dialógicos (Barreto, 1998).

Diante da ineficácia dos programas implantados na região para alfabetizar as crianças amazônidas de forma mais contextualizada, pensou-se na elaboração de uma proposta cuja base fosse a cultura popular local, as experiências de sobrevivência de crianças, a partir de suas vivências no seringal, foi uma sugestão de Bader e Oliveira (1985 apud Carneiro \& Weigel, 1989).

A proposta de uma formação inicial de uma consciência crítica, com base no método Paulo Freire, não se concretizou na região, pois o enfoque em uma educação ambiental reduziu a perspectiva de potencializar as experiências vividas pelos estudantes, residentes nas áreas urbanas aonde o programa chegou. A adoção parcial do método Paulo Freire, limitou a prática pedagógica a apenas partir de uma proposta de recuperação/reforço da cultura popular local (a vida no seringal).

O material elaborado tanto pelo Amazonas quanto pelo Acre, (Carneiro \& Weigel, 1989) partiu da pesquisa participante, mas acabou por privilegiar a proposta de recuperação da identidade cultural sem dá a devida atenção aos problemas existentes na região. De modo que tal concepção de resgate da identidade cultural reafirmou a valorização de aspectos pitorescos do folclore local, desvinculando estórias, mitos e lendas do contexto social, econômico e político das relações sociais que perpassam o cotidiano da população amazônica.

A ideia de resgate cultural tem sido realizada como se a recuperação da identidade cultural fosse uma coisa dada, o que não possibilita espaço para a libertação ideológica ou cultural de processos objetivos de opressão e exploração vigentes. Como se os oprimidos restassem a acomodação a situação (Barreto, 1998).

Essa educação domesticadora, tem servido para a perpetuação desta ordem injusta e desumanizante. Os oprimidos passaram a adapta-se a esta ordem injusta, como se fosse natural, considerando os opressores como modelos bem-sucedidos de seres humanos. Esta estrutura social de dominação desumanizou os oprimidos, ao ponto de negarem a condição de sujeitos agentes de mudança. Por outro lado, também desumanizou os opressores e estes passaram a ver seres humanos como objetos e não como semelhantes (Barreto, 1998). 
Carneiro \& Weigel (1989) evidenciam a necessidade de refletir que o termo educação deve estar associado a concepção de educação como prática social mediadora, historicamente determinada, suscetível a mudanças internas e externas. As práticas educacionais desenvolvidas na Amazônia encontram-se entrelaçadas pelo caráter de subordinação e resistência ao processo de desenvolvimento do capitalismo na região. Assim, é preciso perceber na educação as relações e as forças sociais que formam os opostos no processo que tem determinado as ações da política educacional.

A questão da educação na Amazônia requer reflexões acerca de temas cruciais para sua concretização. Aos responsáveis pelos anos iniciais da educação fundamental cabe ainda pensar sobre as situações sazonais como as identificadas por Carneiro e Weigel (1989), pois ora são a enchente ou a vazante, a maré ou outras condições da natureza, ora o trabalho na agricultura, ou no extrativismo, que suscitam atenção por parte dos envolvidos para que ocorra a efetivação do direito à educação. Processos de migrações rural e urbana, constituição de novas territorialidades na capital e interior, entre outras situações peculiares a realidade local.

Barreto (1998) expressa que somente os oprimidos poderão romper com esta estrutura que desumaniza opressores e oprimidos, pois exclusivamente estes sentem o peso da desigualdade social em seu cotidiano. Os opressores não sairão de suas zonas de conforto e privilégios para orquestrar a mudança estrutural que a humanidade requer.

Salienta-se a importância fundamental do papel do professor no processo de construção da nova estrutura social, da construção de relações sociais mais humanizadas e igualitárias. Contudo, essa é uma missão árdua e depende de um longo processo de despertar da consciência humana.

\section{Conclusão}

Os autores citados no decorrer deste artigo, não apresentam respostas prontas as demandas enfrentas pela questão da educação, seja no panorama local ou global, pelo contrário, a proposta de tais autores é elevar as discussões aos mais diversos espaços educacionais e levar as educadoras/res a pensar a reforma da escola e da sociedade que se quer formar e/ou (re) formar.

As discussões apontam muitas direções, a fim de refletir uma pedagogia para a descolonialidade. Com o intuito de descontinuar, de desviar da ideologia educacional do sistema capitalista que vem anulando as potencialidades das classes subalternas. A propositura de uma pedagogia crítica é um ato de elevação do discurso da esperança das classes subalternizadas.

A compreensão da relação histórica e econômica do contexto social que cerca a prática educacional em diferentes sociedades é o fio condutor da força motriz da elaboração de uma possível mudança nas políticas educacionais. Pensar e elaborar uma educação para despertar a esperança nos grupos periféricos e marginais concentrados nas áreas urbanas e rurais dos distintos espaços amazônicos é um desafio imensurável, porém necessário e urgente.

Assim, é preciso acreditar e plantar as sementes de esperanças em meio ao cenário de desconfiança e desilusão gerado pelo capitalismo nos mais diversos espaços em que dissolveu expectativas de transformação da condição humana, limitando as pessoas a liquidez dos centros comerciais, a banalização da vida. Aos educadores está posto o desafio de reafirmar seu papel na construção de uma sociedade mais justa, igualitária, onde as pessoas, sobretudo as mais pobres, possam ter consciência do compromisso histórico com a transformação social.

Espera-se que, novos resultados no que tange a educação como prática de cultura na Amazônia, venham ser cada vez mais ampliada e aprofundada. Pois as práticas educativas no contexto amazônico são diversas e complexas. Por isso, entender a educação como prática de cultural, é promover o conhecimento da Amazônia. 


\section{Agradecimentos}

As agências de fomento, a Coordenação de Aperfeiçoamento de Pessoal de Nível Superior (CAPES), a Fundação de Amparo à Pesquisa no Estado do Amazonas (FAPEAM), e à Secretária de Estado de Educação e Desporto do Amazonas (SEDUC/AM),

\section{Referências}

Barreto, V. (1998). Paulo Freire para educadores. Arte \& Ciência.

Carneiro, V. da L., \& Weigel, V. A. C. de M. (1989). Contribuições ao texto “A questão da educação na Amazônia. http://www.bibliotecadigital.a ong.org.br/handle/11465/1676

Chizzotti, A. (2003). A pesquisa qualitativa em ciências humanas e sociais: evolução e desafios. Revista Portuguesa de Educação, 16(2). Universidade do Moinho, Braga, Portugal. pp. 221-236.

Fuentes Felicó, N. (2017). Cultura, competência comunicativa e desenvolvimento profissional dos especialistas museológicos / Cultura, competência comunicativa e desenvolvimento profissional dos especialistas museológicos. Transformación, 13(2), 315- 325. https://revistas.reduc.edu.cu/

Habowski, A. C.; Conte, E., \& Trevisan, A. L. (2019). Por uma cultura reconstrutiva dos sentidos das tecnologias na educação. Educ. Soc. 2019, 40, e0218349https://doi.org/10.1590/es0101-73302019218349.

Hall, S. (2006). A identidade cultural na pós-modernidade. Tradução Tomaz Tadeu da Silva, Guaracira Lopes Louro. (11a ed.). DP\&A.

Koche, J. C. (2011). Fundamentos de metodologia científica. Petrópolis: Vozes. http://www.brunovivas.com/wp-content/uploads/sites/10/2018/07 /K\%C3\%B6che-Jos\%C3\%A9-Carlos0D0AFundamentos-de-metodologia-cient\%C3\%ADfica-_-teoria-da0D0Aci\%C3\%AAncia-e-inicia\%C3\%A7\%C3\%A3o$\% \mathrm{C} 3 \% \mathrm{~A} 0$-pesquisa.pdf

Lima, G. C, \& Silva, S. B. (2020). Juventudes Rurais e Processos Educativos. Research, Society and Development, 9(11), e98591110691.

Lima, V. da S., Nunes, A., \& Braga, E. dos S. de O. (2020). Oralidade africana e cultura afro-brasileira no ambiente educacional: algumas reflexões. Research, Society and Development, 9(4), e99942888. https://doi.org/10.33448/rsd-v9i4.2888

Loureiro, V. R. (2012). A Amazônia no século 21: novas formas de desenvolvimento. Revista Direito GV, 8(2), 527-552.

Lousada, E. V., Costa, K. M., \& Santos, O. Q. dos. (2020). A Constituição da Identidade Ribeirinha: Interface Linguagem e Cultura. Revista Amazônida: Revista Do Programa De Pós-Graduação Em Educação Da Universidade Federal Do Amazonas, 4(2), 01-18. https://doi.org/10.29280/rappge.v4i2.5531

Ludke, M. \& André, M. E. D. A. (2013). Pesquisas em educação: uma abordagem qualitativa. E.P.U.

Marques, E. de S. A., \& Carvalho, M. V. C. de. (2019). Vivência e prática educativa. Obutchénie: Revista De Didática E Psicologia Pedagógica, 3(2), 1-25. https://doi.org/10.14393/OBv3n2.a2019-51563

Mclaren, P. (2000). Multiculturalismo crítico. Peter McLaren: prefácio Paulo Freire: apresentação Moacir Gagotti: tradução Bebel Orofino Schaefer. (3a ed.), Cortez: Instituto Paulo Freire.

Mészáros, I. (2008). A educação para além do capital. István Mészarós; tradução Isa Tavares. (2a ed.), Boitempo.

Mészáros, I. (2011). Para além do capital: rumo a uma teoria da transição / István Mészarós; tradução Paulo Cezar Castanheira, Sérgio Lessa. Boitempo.

Mezzaroba, C. (2020). Cultura escolar e cultura midiática enquanto "gramáticas estruturantes": reflexões, possibilidades e limites. Revista Amazônida: Revista Do Programa De Pós-Graduação Em Educação Da Universidade Federal Do Amazonas, 4(2), 01-26. https://doi.org/10.29280/rappge.v4i2.5847

Morales, M. V., Sánchez, J. L., \& Zúñiga, G. V. (2017). Vislumbres para a relevância cultural: O conhecimento pedagógico de um professor indígena de cabécar. Research, Society and Development, 5(3), 173-208. https://doi.org/10.17648/rsd-v5i3.113

Morin, E. (2003). A cabeça bem-feita: repensar a reforma, reformar o pensamento/ Edgar Morin; tradução: Eloá Jacobina. (8a ed.), Bertrand Brasil.

Nascimento, C. A. R., Souza, Érica de S. e, Pereira, L. B., \& Simas, H. C. P. (2021). Educação Superior Indígena na perspectiva da Interculturalidade. Research, Society and Development, 10(2), e59110212979. https://doi.org/10.33448/rsd-v10i2.12979

Oliveira, M. de, Peixoto, R., \& Maio, E. R. (2019). A educação enquanto promotora de uma cultura de paz:o foco nas questões de gênero e sexualidade. Revista Amazônida: Revista Do Programa De Pós-Graduação Em Educação Da Universidade Federal Do Amazonas, 3(2), 27-39. https://doi.org/10.29280/rappge.v3i2.4893

Peixoto, R., \& Santos, S. F. (2021). Lei 10639/2003: reflexões sobre a cultura afro-brasileira e o uso de imagens nos processos educacionais escolares. Research, Society and Development, 10(2), e48310212798. https://doi.org/10.33448/rsd-v10i2.12798

Pereira, A. S. et al. (2018). Metodologia da pesquisa científica. UFSM. https://www.ufsm.br/app/uploads/sites/358/2019/02/Metodologia-da-PesquisaCientifica_final.pdf 
Research, Society and Development, v. 10, n. 3, e46010313605, 2021

(CC BY 4.0) | ISSN 2525-3409 | DOI: http://dx.doi.org/10.33448/rsd-v10i3.13605

Pereira, C. L., \& Pereira, M. R. S. (2020). Etnomatemática escolar indígena: o uso de artefatos socioculturais no ensinar e aprender no Ensino Fundamental I. Research, Society and Development, 9(8), e373985341. https://doi.org/10.33448/rsd-v9i8.5341

Rocha, G., \& Tosta, S. P. (2013). Antropologia \& Educação. (2a ed.), Autêntica.

Santos, A. B.; Machado, J. A. da C., \& Seráfico, M. (2015). Capítulo 4: Formação Socioeconômica do Estado do Amazonas. In: Castro, E. R. de; Campos, Í. (orgs). Formação Socioeconômica da Amazônia - Belém: NAEA, 173-224.

Serpa, L. G., Machado, C. J. dos S., Nascimento, G. A. do, \& Almeida, A. R. de. (2021). Por uma educação a favor da práxis: ação, educação e cultura. Research, Society and Development, 10(1), e54210112104. https://doi.org/10.33448/rsd-v10i1.12104

Silva, M. A. da C. (2019). Influência da cultura na educação. Revista Científica Multidisciplinar Núcleo do Conhecimento. 11, 114-128. https://www.nucleodoconhecimento.com.br/educacao/cultura-na-educacao

Testa, W. L. (2020). Educação lazer e saúde: relato metodológico de educação a distância durante a pandemia do Covid-19. Research, Society and Development, 9(12), e19491210881.

Vasconcelos, M. E. de O. (2017). Educação do Campo no Amazonas: história e diálogos com a territorialidade das águas, das terras e das florestas. Tese (Doutorado). Universidade Federal do Pará. Belém. 